\title{
Multi-step radical spiro-cyclization of an alkynylaryl isothiocyanate
}

\author{
Matteo Minozzi, ${ }^{\dagger}$ Daniele Nanni, ${ }^{\dagger *}$ Giuseppe Zanardi, $^{\dagger *}$ and Gianluca Calestani ${ }^{\dagger}$ \\ † Dipartimento di Chimica Organica "A. Mangini", Università di Bologna, Viale Risorgimento 4, \\ I-40136 Bologna, Italy \\ ‡ Dipartimento di Chimica Generale ed Inorganica, Analitica e Chimica Fisica, Università di \\ Parma, Viale delle Scienze 78, I-43100 Parma, Italy \\ E-mail: nanni@ms.fci.unibo.it
}

This paper is dedicated to Professor Giuseppe Bartoli on the occasion of his $65^{\text {th }}$ birthday

\begin{abstract}
Cyclohexyl radicals, generated by decomposition of dibenzoyl peroxide in cyclohexane, add to 2-(2-phenylethynyl)phenyl isothiocyanate to afford thioimidoyl radicals. Despite the unfavorable fragmentation equilibrium, these radicals give rise to a multi-step cyclization/H-translocation process yielding a spiranic polycondensed heterocyclic compound. An analogous spiranic dihydro-derivative is obtained by reaction of the corresponding alkynyl isonitrile with cyclohexanethiol under radical conditions.
\end{abstract}

Keywords: Radicals, cyclizations, rearrangements, isothiocyanates, isonitriles

\section{Introduction}

Since the discovery of several annulations based around their formation from imines or isonitriles, ${ }^{1,2}$ imidoyl radicals $\left(\mathrm{R}^{1} \mathrm{~N}=\mathrm{C}^{\bullet} \mathrm{R}^{2}\right)$ have been established as very interesting synthetic intermediates. ${ }^{3}$ Thioimidoyl radicals $\left(\mathrm{R}^{1} \mathrm{~N}=\mathrm{C}^{\bullet} \mathrm{SR}^{2}\right)$, in particular, can be generated from sulfanyl radical additions to isonitriles ${ }^{3}$ or by aryl radical additions to isothiocyanates, and important cyclization and cascade sequences involving these intermediates have been developed recently, including the syntheses of various heterocyclic compounds ${ }^{4,5}$ and a novel tin-free procedure for alkyl radical generation. ${ }^{6}$

Recently, we have studied the addition of alkylsulfanyl radicals to alkyl isonitriles (Scheme 1, path $a$ ) and characterized the resulting imidoyl radicals by EPR spectroscopy. ${ }^{7}$ The rate constants and activation energies for the $\beta$-scissions of their $\mathrm{C}^{\bullet}-\mathrm{S}$ bonds have been calculated, showing that the fragmentation rates, although depending on the stability of the released alkyl radicals, are in any case very fast at r.t. and above. When a cyclization can occur, this competes 
only at low temperatures. ${ }^{7 a}$ On this basis, the alternative generation of alkylthioimidoyls by addition of alkyl radicals to isothiocyanates can be assumed as an equilibrium reaction which is almost completely shifted towards the reagents (Scheme 1, path $b$ ). This is the reason why thioimidoyls can be efficiently employed in cascade reactions only when they are generated by addition of aryl radicals to isothiocyanates (Scheme 1 , path $b, \mathrm{R}^{2}=\mathrm{Ar}$ ), ${ }^{5}$ owing to their strong Saryl bond. To date there are instead no synthetic applications of analogous generation of the alkyl counterparts, although cyclizations have been observed by addition of primary alkylsulfanyl radicals to alkenyl- and alkynyl isonitriles. ${ }^{4 a}$

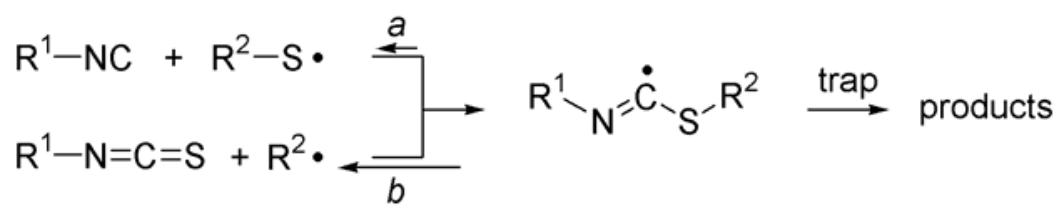

\section{Scheme 1}

Here we report the first example of cyclization of thioimidoyl radicals generated by addition of cyclohexyl radicals to an alkynyl isothiocyanate. The unusual multi-step process involves two cyclizations linked by a hydrogen-atom transfer and affords an uncommon spiranic polycondensed heterocycle.

\section{Results and Discussion}

When 2-(2-phenylethynyl)phenyl isothiocyanate $\mathbf{1}^{5 \mathrm{c}}$ was allowed to react with dibenzoyl peroxide in boiling cyclohexane, only trace amounts of the product (3) arising from the expected addition of phenyl radicals to $\mathbf{1}$ were detected. ${ }^{5 \mathrm{c}}$ The reaction furnished instead the spirocompound 2 in $40 \%$ yield (Scheme 2). The structure of 2 was established by NMR spectral analysis (see Experimental Section) and was eventually confirmed by X-ray diffraction (Figure 1, see also Supporting Information).

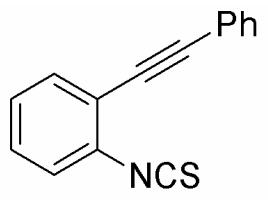

1

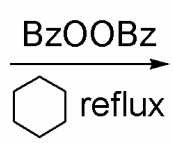

reflux

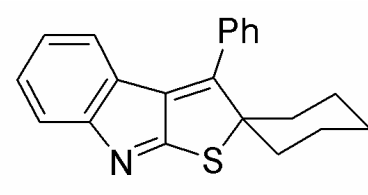

2

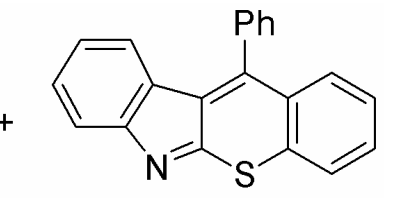

3

\section{Scheme 2}

Product 2 can be accounted for through initial generation of cyclohexyl radicals by hydrogen abstraction from the solvent cyclohexane by benzoyloxy radicals. This process competes very 
efficiently with decarboxylation of the latter to give phenyl radicals and then compound 3 therefrom (Scheme 3, blue pathway). Addition of cyclohexyl radicals to $\mathbf{1}$ affords thioimidoyls $\mathbf{4}$, which can cyclize onto the $\mathrm{C}-\mathrm{C}$ triple bond in a 5-exo-dig fashion to afford vinyl radicals $5 .{ }^{8}$ The presumably very high cyclization rate would trap the thioimidyls $\mathbf{4}$ before reverse fragmentation to the starting material (see Scheme 1). The vinyl radicals 5 can most likely rearrange through 1,5-hydrogen translocation from the $\mathrm{S}-\mathrm{CH}$ moiety to give alkyl radicals $\mathbf{6}$, which eventually cyclize onto the $\mathrm{C}-\mathrm{C}$ double bond in a 5-endo-trig fashion ${ }^{9}$ to yield the highly delocalized radical 7 and thence the final product 2 after hydrogen abstraction (Scheme 3, black pathway).

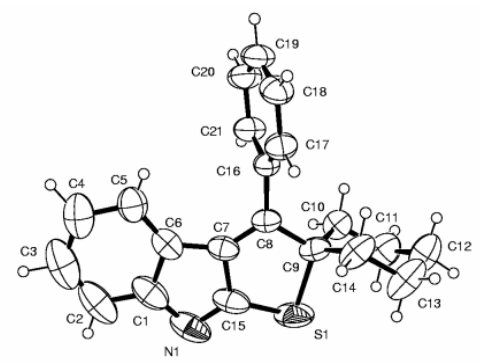

Figure 1. ORTEP view of spiro-compound 2.

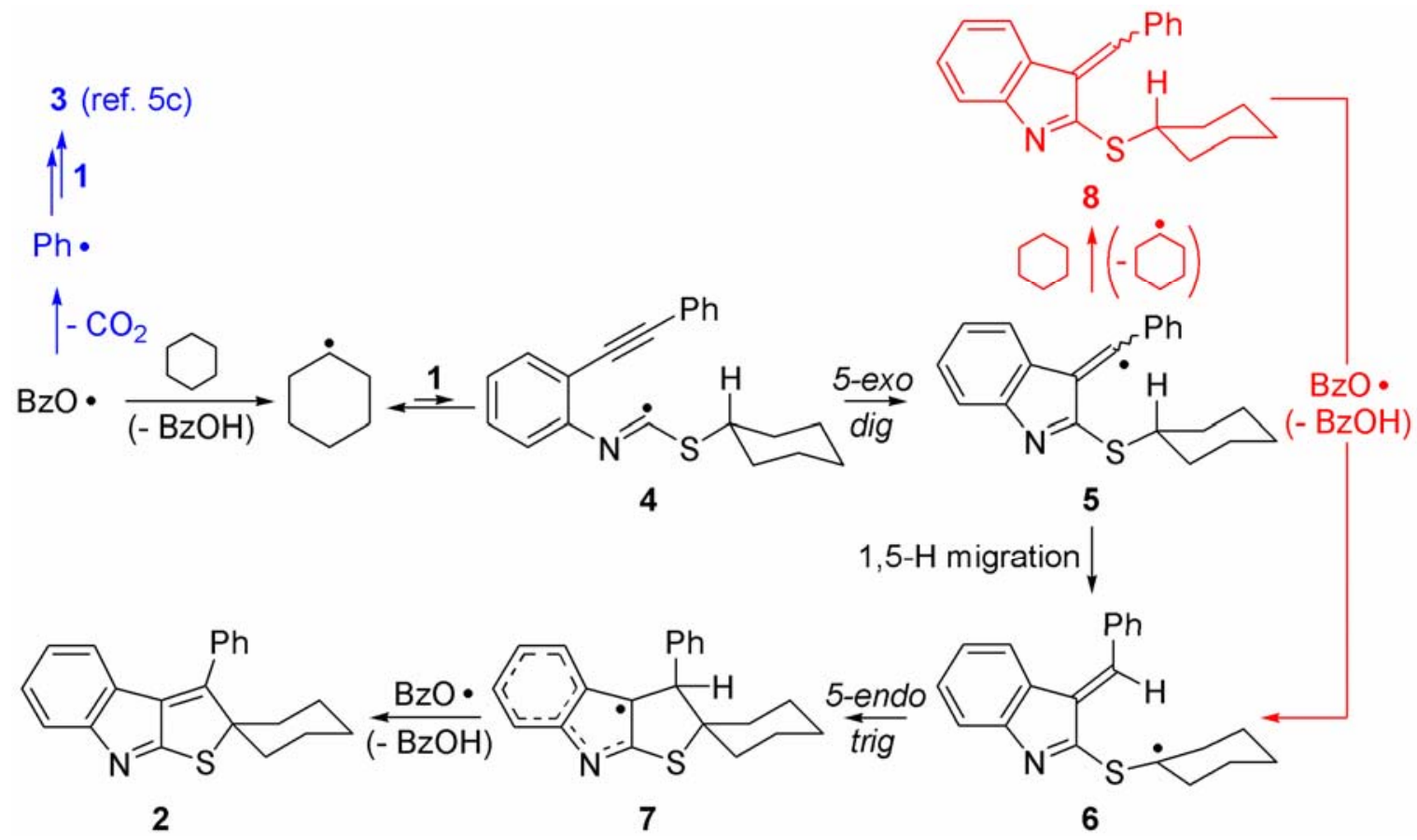

\section{Scheme 3}

We cannot exclude the possibility that the highly reactive vinyl radicals 5 could be trapped by the solvent and then benzoyloxy radicals could restart the cyclization process by abstracting the S-CH hydrogen, hence giving the final compound (Scheme 3, red pathway). However, 
intramolecular hydrogen migration towards a vinyl radical should be a fast process, especially when a stabilized alkyl radical is formed, as in the case of $\mathbf{6}^{10,11}$ Moreover, DFT calculations suggest that rearrangement of $\mathbf{5}$ into $\mathbf{6}$ by 1,5-hydrogen translocation is a feasible, conformationally favored, exothermic reaction $\left(\Delta \mathrm{H}=-7.1 \mathrm{kcal} \mathrm{mol}^{-1}\right)$ with a low activation barrier of $7.3 \mathrm{kcal} \mathrm{mol}^{-1}$ (see Supporting Information). ${ }^{12}$

To verify the intermediacy of thioimidoyl radicals 4 in the cascade process of Scheme 3, we tried to generate the same intermediates by the alternative, well-known method for producing thioimidoyls, i.e., by treating an isonitrile with sulfanyl radicals. ${ }^{3,4,6} \mathrm{We}$ therefore allowed 2-(2phenylethynyl)phenyl isonitrile 9 to react with cyclohexanethiol in boiling benzene in the presence of AIBN as a radical initiator. The reaction afforded the quinoline 10 (38\%), the spirocompound 2 (6\%), and its dihydro-derivative 11 in 26\% yield (Scheme 4).

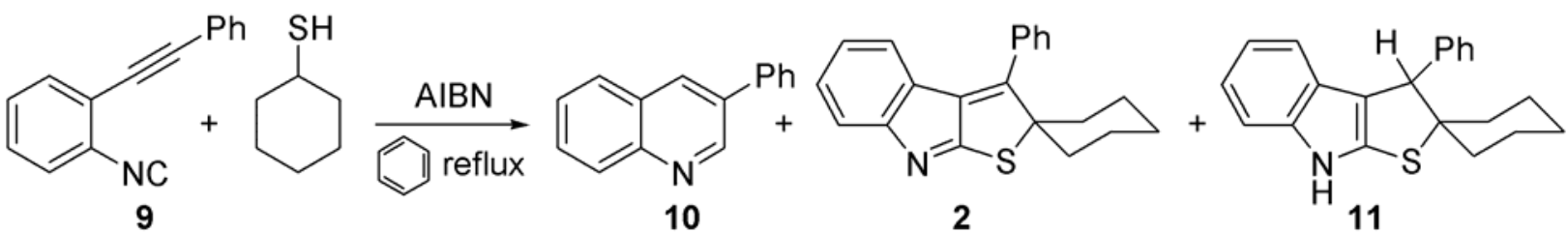

\section{Scheme 4}

In this case, 11 and 2 clearly result from $\mathrm{H}$-abstraction from the thiol and addition of the resulting sulfanyl radical to isonitrile 9 to give the thioimidoyl 4 (Scheme 5); cyclization of the latter onto the $\mathrm{C}-\mathrm{C}$ triple bond followed by 1,5-hydrogen migration and cyclization onto the resulting $\mathrm{C}-\mathrm{C}$ double bond eventually lead to radical 7 , analogously to the reaction of the isothiocyanate $\mathbf{1}$. Both the two cyclizations and the hydrogen translocation seem to be very fast since, in the route to 7, no intermediate radical is trapped by the starting thiol, independently of its concentration and despite its excellent hydrogen-donor capability. ${ }^{13}$

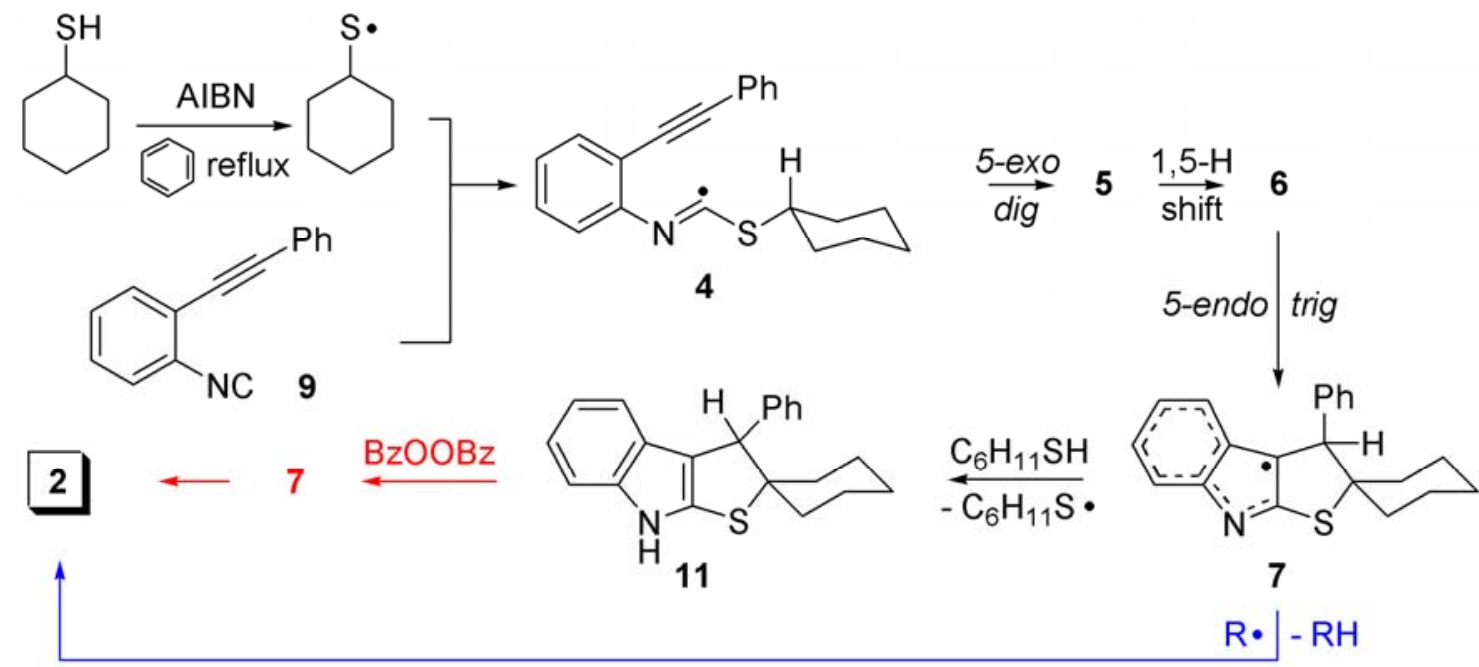

\section{Scheme 5}


Under these conditions, i.e., in the absence of efficient hydrogen abstractors or oxidants, the stable radical 7 hardly evolves to 2 by hydrogen loss (Scheme 5, blue pathway), being preferentially trapped by the thiol to give the dihydro-compound $\mathbf{1 1}$.

Evidence has been reported that vinyl radicals (and also the 1-phenyl-substituted ones) can effectively undergo intramolecular 1,5-hydrogen transfer before being trapped by a thiol, provided (mainly) that a suitably stabilized alkyl radical is formed. ${ }^{10 a, b}$ Due to this information we were hardly surprised that in the reaction shown in Scheme 5, the radicals 5 are able to rearrange before hydrogen transfer from the thiol occurs. The quite unexpected result was that, instead, the nucleophilic alkyl radicals $\mathbf{6}$ originating from the hydrogen translocation can cyclize without being appreciably trapped by the electrophilic thiol, even when this was present in high concentration. $^{14}$

The reaction product $\mathbf{1 1}$ was slowly converted into the spiro-compound $\mathbf{2}$ by ambient oxygen when kept in solution in an open vessel for a few days; it also afforded $\mathbf{2}$ quantitatively when heated for 1 hour in boiling cyclohexane in the presence of dibenzoyl peroxide (Scheme 5, red pathway).

In conclusion, we have showed that the addition of alkyl radicals to isothiocyanates can afford synthetically useful imidoyl radicals, provided that a fast cyclization process could trap the intermediate before its retro-fragmentation. The scope of this reaction and its exploitation in the synthesis of heterocyclic compounds is currently under investigation.

\section{Experimental Section}

General Procedures. ${ }^{1} \mathrm{H}$ - and ${ }^{13} \mathrm{C}$ - NMR spectra were recorded in $\mathrm{CDCl}_{3}$ solutions, using the peaks of the solvent as internal standard. IR spectra were recorded in benzene or $\mathrm{CHCl}_{3}$ solutions. Mass spectra were recorded by the electron impact (EI) method with a beam energy of $70 \mathrm{eV}$ or electron spray ionization (ESI). Column chromatography was performed on silica gel (63-200, $60 \AA$ ) or basic aluminum oxide (activity grade III) by gradual elution with light petroleum $\left(\mathrm{bp}=40-70{ }^{\circ} \mathrm{C}\right) /$ diethyl ether or light petroleum/diethyl ether/dichloromethane mixtures and final elution with dichloromethane and methanol. Dibenzoyl peroxide and cyclohexanethiol (Aldrich) were commercial materials and were used as received. Azo-bis-iso-butyronitrile (AIBN) (Fluka) was recrystallized from $\mathrm{CHCl}_{3} / \mathrm{CH}_{3} \mathrm{OH}$. 2-(2-Phenylethynyl)benzenamine, ${ }^{15}$ 2-(2-phenylethynyl)phenyl isothiocyanate (1), ${ }^{5 \mathrm{c}}$ and 2-(2phenylethynyl)phenyl isonitrile (9) ${ }^{16}$ were prepared according to the literature.

2-(2-Phenylethynyl)phenyl isonitrile (9). Compound 9 has been reported previously ${ }^{16}$ but nothing was known about its stability and spectral data. It was synthesized in almost quantitative yields according to the general method reported in the literature for a TMS congener. ${ }^{16 a}$ To a mixture of $N$-[2-(2-phenylethynyl)phenyl]formamide $(2.67 \mathrm{~g}, 12.3 \mathrm{mmol})$ and triethylamine $(8.60 \mathrm{~mL}, 62 \mathrm{mmol})$ in THF $(40 \mathrm{~mL})$, phosphorous oxychloride $(1.37 \mathrm{~mL}, 14.7 \mathrm{mmol})$ was added dropwise at $0{ }^{\circ} \mathrm{C}$ over $15 \mathrm{~min}$. The mixture was stirred at $0{ }^{\circ} \mathrm{C}$ for $2 \mathrm{~h}$ and then saturated 
aqueous sodium hydrogen carbonate $(50 \mathrm{~mL})$ was added at $0{ }^{\circ} \mathrm{C}$. Extraction with benzene and drying over sodium sulfate gave the target compound $\mathbf{9}$. This could be isolated as a thick, greenblackish oil and, in solution, is stable enough to record NMR and IR spectra; however, it decomposed quite rapidly to give tarry material when kept at r.t. in the absence of solvent. It was therefore extracted with benzene and used for the reaction with cyclohexanethiol without further purification. IR (benzene) $v_{\max }\left(\mathrm{cm}^{-1}\right) 2120(\mathrm{NC}) ;{ }^{1} \mathrm{H}$ NMR $(300 \mathrm{MHz}) \delta 7.33-7.43(6 \mathrm{H}, \mathrm{m})$, 7.56-7.58 (1 H, m), 7.59-7.63 (2 H, m); ${ }^{13} \mathrm{C} \mathrm{NMR} \mathrm{(75} \mathrm{MHz)} \delta 84.38$ (C), 96.75 (C), $106.58(\mathrm{C})$, $121.79(\mathrm{C}), 122.24(\mathrm{C}), 126.52(\mathrm{CH}), 128.41(\mathrm{CH}), 128.74(\mathrm{CH}), 129.00(\mathrm{CH}), 129.06(\mathrm{CH})$, $131.89(\mathrm{CH}), 132.18(\mathrm{CH})$ (the $\mathrm{NC}$ quaternary carbon is missing, but is clearly visible in the IR spectrum).

Reaction of isothiocyanate 1 with dibenzoyl peroxide in cyclohexane. A cyclohexane $(20 \mathrm{~mL})$ solution of 1 ( $0.5 \mathrm{~g}, 2 \mathrm{mmol})$ and dibenzoyl peroxide $(2.0 \mathrm{~g}, 8 \mathrm{mmol})$ was refluxed for $24 \mathrm{~h}$. The final mixture was evaporated and the residue chromatographed first on silica gel and then on aluminum oxide eluting with light petroleum/diethyl ether/dichloromethane (80:10:10).

Reaction of isonitrile 9 with cyclohexanethiol. A benzene $(80 \mathrm{~mL})$ solution of $9(2.5 \mathrm{mmol})$, cyclohexanethiol $(2.5 \mathrm{mmol})$, and $\operatorname{AIBN}(0.5 \mathrm{mmol})$ was stirred for $2 \mathrm{~h}$ at $80{ }^{\circ} \mathrm{C}$. In a subsequent experiment with lower thiol concentration, a benzene $(10 \mathrm{~mL})$ solution of cyclohexanethiol $(2.5$ mmol) and AIBN ( $0.4 \mathrm{mmol})$ was added by a syringe pump over $2 \mathrm{~h}$ to a refluxing benzene (70 $\mathrm{mL})$ solution of 9 and AIBN $(0.1 \mathrm{mmol})$. After evaporation of the solvent, the residue was purified by column chromatography on silica gel, eluting with light petroleum/diethyl ether mixtures as indicated below.

\section{Reaction products}

3'-Phenylspiro[cyclohexane-1,2'-thieno[2,3-b]indole] (2). Yellow-orange solid, mp 191-193 ${ }^{\circ} \mathrm{C}$ (from aqueous ethanol), crystals suitable for X-ray diffraction were obtained by slow evaporation of a chloroform solution; yields $=40 \%$ (from 1) and $6 \%$ (from 9). IR $\left(\mathrm{CHCl}_{3}\right) v_{\max }$. $\left(\mathrm{cm}^{-1}\right)$ 2938, 1508; MS m/e (rel. int.) $317\left(\mathrm{M}^{+}, 100\right), 288$ (24), 284 (35), 260 (15); ${ }^{1} \mathrm{H}$ NMR (400 $\mathrm{MHz}) \delta 1.15\left(2 \mathrm{H}, \mathrm{qt}, J_{q}=13.3 \mathrm{~Hz}, J_{t}=3.7 \mathrm{~Hz}\right), 1.60-1.72(2 \mathrm{H}, \mathrm{m}), 1.92-2.00(6 \mathrm{H}, \mathrm{m}), 6.81-$ $6.88(2 \mathrm{H}, \mathrm{m}), 7.26\left(1 \mathrm{H}, \mathrm{ddd}, J_{1}=7.7 \mathrm{~Hz}, J_{2}=7.1 \mathrm{~Hz}, J_{3}=1.6 \mathrm{~Hz}\right), 7.31-7.34(2 \mathrm{H}, \mathrm{m}), 7.41$ (1 $\mathrm{H}$, ddd, $\left.J_{1}=7.9 \mathrm{~Hz}, J_{2}=0.8 \mathrm{~Hz}, J_{3}=0.8 \mathrm{~Hz}\right), 7.50-7.54(3 \mathrm{H}, \mathrm{m}) ;{ }^{13} \mathrm{C} \mathrm{NMR}(100 \mathrm{MHz}) \delta 24.5$ $\left(\mathrm{CH}_{2}\right), 26.1\left(\mathrm{CH}_{2}\right), 36.1\left(\mathrm{CH}_{2}\right), 81.5(\mathrm{C}), 118.7(\mathrm{CH}), 122.4(\mathrm{CH}), 122.7(\mathrm{CH}), 125.7(\mathrm{C}), 128.0$ $(\mathrm{CH}), 128.8(\mathrm{CH}), 129.0(\mathrm{CH}), 129.7(\mathrm{CH}), 133.9(\mathrm{C}), 140.8(\mathrm{C}), 158.7(\mathrm{C}), 163.7(\mathrm{C}), 181.5$ (C). Anal. calcd. for $\mathrm{C}_{21} \mathrm{H}_{19} \mathrm{NS}$ : C, 79.45; H, 6.03; N, 4.41. Found: C, 79.70; H, 6.01; N, 4.40 .

11-Phenylthiochromeno[2,3-b]indole (3). Yield, trace amounts. See ref. 5c for spectroscopic data.

3-Phenylquinoline (10). Eluted with light petroleum/diethyl ether $80: 20 \mathrm{v} / \mathrm{v} ;$ yield $=38 \% ;{ }^{1} \mathrm{H}$ NMR $(300 \mathrm{MHz}) \delta 7.41-7.76(7 \mathrm{H}, \mathrm{m}), 7.88\left(1 \mathrm{H}, \mathrm{dd}, J_{1}=8.0 \mathrm{~Hz}, J_{2}=1.3 \mathrm{~Hz}\right), 8.15\left(1 \mathrm{H}, \mathrm{dd}, J_{1}\right.$ $\left.=8.5 \mathrm{~Hz}, J_{2}=1.1 \mathrm{~Hz}\right), 8.3(1 \mathrm{H}, \mathrm{d}, J=2.2 \mathrm{~Hz}), 9.19(1 \mathrm{H}, \mathrm{d}, J=2.4 \mathrm{~Hz})\left[\operatorname{lit}^{17}{ }^{1} \mathrm{H} \mathrm{NMR}(300\right.$ MHz) $\delta 7.5(7 \mathrm{H}, \mathrm{m}), 7.83\left(1 \mathrm{H}, \mathrm{dd}, J_{1}=8.1 \mathrm{~Hz}, J_{2}=1.0 \mathrm{~Hz}\right), 8.08(1 \mathrm{H}, \mathrm{d}, J=8.4 \mathrm{~Hz}), 8.25(1$ $\mathrm{H}, \mathrm{d}, J=2.1 \mathrm{~Hz}), 9.13(1 \mathrm{H}, \mathrm{d}, J=2.3 \mathrm{~Hz})]$. 
3'-Phenyl-3',8'-dihydrospiro[cyclohexane-1,2'-thieno[2,3-b]indole] (11). Eluted with light petroleum/diethyl ether 95:5 v/v; oil; yield $=26 \%$; IR $\left(\mathrm{CHCl}_{3}\right) v_{\max }\left(\mathrm{cm}^{-1}\right) 3470,3018,2934$, 1447; MS (ESI) $318(\mathrm{M} \mathrm{-} \mathrm{1)})^{-}{ }^{1} \mathrm{H}$ NMR (400 MHz) $\delta$ 1.05-1.84 (9 H, m), 2.41 (1 H, br. d, $J=$ $13.3 \mathrm{~Hz}), 4.29(1 \mathrm{H}, \mathrm{s}), 6.88-6.94(2 \mathrm{H}, \mathrm{m}), 6.99\left(1 \mathrm{H}, \mathrm{ddd}, J_{1}=8.0 \mathrm{~Hz}, J_{2}=6.0 \mathrm{~Hz}, J_{3}=2.3 \mathrm{~Hz}\right)$, 7.19-7.30 (6 H, m), 7.82 (1 H, br. s); ${ }^{13} \mathrm{C}$ NMR (100 MHz) $\delta 24.45\left(\mathrm{CH}_{2}\right), 24.72\left(\mathrm{CH}_{2}\right), 25.39$ $\left(\mathrm{CH}_{2}\right), 35.67\left(\mathrm{CH}_{2}\right), 40.44\left(\mathrm{CH}_{2}\right), 58.43(\mathrm{CH}), 79.16(\mathrm{C}), 110.71(\mathrm{CH}), 119.19(\mathrm{CH}), 119.25(\mathrm{C})$, $119.77(\mathrm{CH}), 119.84(\mathrm{CH}), 125.72(\mathrm{C}), 126.98(\mathrm{CH}), 127.97(\mathrm{CH}), 129.45(\mathrm{CH}), 137.06(\mathrm{C})$, 138.74 (C), 140.48 (C). Anal. calcd. for $\mathrm{C}_{21} \mathrm{H}_{21} \mathrm{NS}$ : C, 78.95; H, 6.63; N, 4.38. Found: C, 79.27; $\mathrm{H}, 6.61 ; \mathrm{N}, 4.36$.

\section{Supplementary information available}

Calculation details, Cartesian matrices and structures of radicals $\mathbf{5}$ and $\mathbf{6}$ and the transition state for 1,5-H transfer. X-ray molecular structure, crystal data and structure refinements, and CIF file of compound 2.

\section{Acknowledgements}

We gratefully acknowledge financial support from MIUR (2004-2005 funds for "Free Radicals in Oxidation Reactions and in New Synthetic Processes") and the University of Bologna (20012003 Funds for Selected Research Topics).

\section{References and notes}

1. (a) Leardini, R.; Pedulli, G. F.; Tundo, A.; Zanardi, G. J. Chem. Soc., Chem. Commun. 1984, 1320. (b) Leardini, R.; Nanni, D.; Pedulli, G. F.; Tundo, A.; Zanardi, G. J. Chem. Soc., Perkin Trans. 1 1986, 1591. (c) Leardini, R.; Nanni, D.; Tundo, A.; Zanardi, G. J. Chem. Soc., Chem. Commun. 1989, 757. (d) Leardini, R.; Nanni, D.; Tundo, A.; Zanardi, G. Gazz. Chim. It. 1989, 119, 637. (e) Curran, D. P.; Liu, H. J. Am. Chem. Soc. 1991, 113, 2127. (f) Ryu, I.; Sonoda, N.; Curran, D. P. Chem. Rev. 1996, 96, 177. (g) Josien, H.; Ko, S. -B.; Bom, D.; Curran, D. P. Chem. Eur. J. 1998, 4, 67.

2. Other processes involving imidoyl radicals: (a) Nanni, D.; Pareschi, P.; Rizzoli, C.; Sgarabotto, P.; Tundo, A. Tetrahedron 1995, 51, 9045. (b) Nanni, D.; Pareschi, P.; Tundo, A. Tetrahedron Lett. 1996, 37, 9337. (c) Camaggi, C. M.; Leardini, R.; Nanni, D.; Zanardi, G. Tetrahedron 1998, 54, 5587. (d) Leardini, R.; Nanni, D.; Zanardi, G. J. Org. Chem. 2000, $65,2763$. 
3. For a review on radical addition to isonitriles see: Nanni, D. in Radicals in Organic Synthesis, Vol. 2 (Renaud, P.; Sibi, M. P., Eds.), Wiley-VCH, Weinheim, 2001, ch 1.3.1, pp. 44-61.

4. (a) Bachi, M. D.; Balanov, A.; Bar-Ner, N. J. Org. Chem. 1994, 59, 7752. (b) Bachi, M. D.; Melman, A. Synlett. 1996, 60. (c) Bachi, M. D.; Melman, A. J. Org. Chem. 1997, 62, 1896. (d) Bachi, M. D.; Melman, A. Pure Appl. Chem. 1998, 70, 259.

5. (a) Leardini, R.; Nanni, D.; Pareschi, P.; Tundo, A.; Zanardi, G. J. Org. Chem. 1997, 62, 8394. (b) Benati, L.; Leardini, R.; Minozzi, M.; Nanni, D.; Spagnolo, P.; Zanardi, G. J. Org. Chem. 2000, 65, 8669. (c) Benati, L.; Calestani, G.; Leardini, R.; Minozzi, M.; Nanni, D.; Spagnolo, P.; Strazzari, S.; Zanardi, G. J. Org. Chem., 2003, 68, 3454.

6. Benati, L.; Leardini, R.; Minozzi, M.; Nanni, D.; Scialpi, R.; Spagnolo, P.; Strazzari, S.; Zanardi, G. Angew. Chem. Int. Ed. 2004, 43, 3598.

7. (a) Minozzi, M.; Nanni, D.; Walton, J. C. Org. Lett. 2003, 5, 901. (b) Minozzi, M.; Nanni, D.; Walton, J. C. J. Org. Chem. 2004, 69, 2056.

8. 1-Substituted vinyl radicals can be linear- $\pi$, or bent, rapidly inverting $\sigma$-radicals, depending on the substituent. Whereas a TMS group is commonly accepted to give rise to linear radicals, the structure of the 1-phenyl congeners is more debatable - see: (a) Ito, O.; Omuri, R.; Matsuda, M. J. Am. Chem. Soc. 1982, 104, 3934. (b) Benati, L.; Montevecchi, P. C.; Spagnolo, P. J. Chem. Soc., Perkin Trans 1 1991, 2103. (c) Guerra, M. Res. Chem. Intermediat. 1996, 22, 369. This is the reason for a wavy bond being used for the $\mathrm{C}^{\bullet} \mathrm{Ph}$ connection in radical 5.

9. The 5-endo-trig radical cyclization mode is very uncommon, but in our case it could be thermodynamically favored by the high delocalization of the resulting radical 7. A few bona fide examples of 5-endo-trig radical cyclizations have however been reported; see: (a) Mendenhall, G. D.; Protasiewicz, J. D.; Brown, C. E.; Ingold, K. U.; Lusztyk, J. J. Am. Chem. Soc. 1994, 116, 1718. (b) Sato, T.; Machigashira, N.; Ishibashi, H.; Ikeda, M. Heterocycles 1992, 33, 139. (c) Ishibashi, H.; Nakamura, N.; Sato, T.; Takeuchi, M.; Ikeda, M. Tetrahedron Lett. 1991, 32, 1725. (d) Sato, T.; Nakamura, N.; Ikeda, K.; Okada, M.; Ishibashi, H.; Ikeda, M. J. Chem. Soc., Perkin Trans. 1 1992, 2399.

10. For recent examples of hydrogen translocation to vinyl radicals, see: (a) Capella, L.; Montevecchi, P. C.; Navacchia, M. L. J. Org. Chem. 1996, 61, 6783. (b) Montevecchi, P. C.; Navacchia, M. L. J. Org. Chem. 1997, 62, 5600. (c) Kunishima, M.; Hioki, K.; Kono, K.; Kato, A.; Tani, S. J. Org. Chem. 1997, 62, 7542. (d) Sha, C. -K.; Ho, W. -Y.; Mohanakrishnan, A. K.; Lin, C. -L.; Chu, S. -Y. C. R. Acad. Sci. Paris 2001, 4, 439.

11. It is worth noting that if $\mathbf{5}$ would give hydrogen abstraction from the solvent it should afford a mixture of cis- and trans-phenylmethylidene compounds $\mathbf{8}$, with the geometry of the former not being very suitable for the subsequent cyclization. However, no traces of such a compound were detected in our reaction mixtures. On the other hand, 1,5-hydrogen migrations in alkyl radicals are fast processes, which generally occur with activation barriers that - in the case of tertiary hydrogens - are presumably lower than $15 \mathrm{kcal} \mathrm{mol}^{-1}$; for 
theoretical studies, see: Huang, X. L.; Dannenberg, J. J. J. Org. Chem. 1991, 56, 5421. Viskolcz, B.; Lendvay, G.; Seres, L. J. Phys. Chem. A 1997, 101, 7119.

12. DFT calculations found for radical 5 a minimum of the energy surface characterized by a structure containing the $\mathrm{S}-\mathrm{CH}$ hydrogen conformationally close to the vinyl radical center, and therefore in the suitable position for the 1,5-shift. In the optimized transition state, the $\mathrm{SC}-\mathrm{H}$ and $\mathrm{C}^{\bullet}---\mathrm{H}$ distances (1.311 and $1.415 \AA$, respectively) and the $\mathrm{C}-\mathrm{H}---\mathrm{C}$ angle $\left(160.5^{\circ}\right)$ are consistent with other calculated transition states for $1,5-\mathrm{H}$ rearrangements of alkyl radicals (ref. 11): see also the Supporting Information.

13. When the thiol was all added to the starting reaction mixture the results reported in the text were obtained; when the thiol was added slowly in two hours by a syringe pump, the quinoline 10 and compound 2 were the only reaction products. The formation of the quinoline $\mathbf{1 0}$ has not been rationalized yet. The ability of isonitriles to behave like hydrogenatom abstractors (see ref. 2a) suggests that $\mathbf{9}$ could abstract a hydrogen from radical 7 to afford the final spiro-compound $\mathbf{2}$ and, concomitantly, an imidoyl radical that might cyclize onto the $\mathrm{C}-\mathrm{C}$ triple bond to give 10. This explanation, however, can only partially explain our result, since it should involve the formation of comparable amounts of $\mathbf{1 0}$ and 2, that is not our case. Quinoline $\mathbf{1 0}$ is not in any case the result of an electrocyclization process of isonitrile $\mathbf{9}$, since no trace of $\mathbf{1 0}$ was obtained when $\mathbf{9}$ was refluxed in benzene for several hours in the absence of other reagents.

14. (a) Feray, L.; Kuznetsov, N.; Renaud, P. in Radicals in Organic Synthesis, Vol. 2 (Renaud, P. and Sibi, M. P. Eds.), Wiley-VCH, Weinheim, 2001, pp. 246-278. (b) Bertrand, M. P.; Ferreri, C. in Radicals in Organic Synthesis, Vol. 2 (Renaud, P. and Sibi, M. P. Eds.), Wiley-VCH, Weinheim, 2001, pp. 485-504.

15. Castro, C. E.; Gaughan, E. J.; Owsley, D. C. J. Org. Chem. 1966, 31, 4071.

16. (a) Suginome, M.; Fukuda, T.; Ito, Y. Org. Lett. 1999, 1, 1977. (b) Rainier, J. D.; Kennedy, A. R.; Chase, E. Tetrahedron Lett. 1999, 40, 6325.

17. Mongin, F.; Mojovic, L.; Guillamet, B.; Trécourt, F.; Quéguiner, G. J. Org. Chem. 2002, 67, 8991. 